\title{
Identification of trends and wave regularities according to statistical data of fluctuations of mass of glaciers
}

\section{P.M. Mazurkin}

Doctor of Engineering, professor, Academician of Russian Academy of Natural History and Russian Academy of Natural Sciences, member of the European Academy of Natural sciences, Volga State University of Technology, Yoshkar-Ola, Russia, kaf_po@mail.ru

\begin{abstract}
The method of identification is shown on the example of tabular data of measurements of six parameters of subgroup of EEE on fluctuations in 2013 at balance of mass of 2528 glaciers of Earth. The equations of a trend and oscillatory indignations on the basis of steady laws on the generalized wave function in the form of an asymmetric wavelet signal with variables of amplitude and the period of fluctuation are received. Schedules of components of the generalized model of a wavelet signal allow to see visually a picture of mutual influence of all six parameters of subgroup of EEE at fluctuations of mass of glaciers. On the revealed equations it is possible to carry out the amplitude-frequency analysis.
\end{abstract}

Keywords: glaciers, fluctuation, balance of weight, factors, regularities

\section{Introduction}

Unlike deductive approach to wavelet analysis proceeding from the equations of classical mathematics inductive approach when statistical selection is primary is offered and concerning it the structure and values of parameters of the generalized wave function [1-18] is identified.

Any phenomenon (time cut) or process (change in time) according to sound tabular statistical quantitative data (a numerical field) inductively can be identified the sum of asymmetric wavelet signals of a look

$$
\begin{array}{r}
y=\sum_{i=1}^{m} y_{i}, y_{i}=A_{i} \cos \left(\pi x / p_{i}-a_{8 i}\right), \\
A_{i}=a_{1 i} x^{a_{2 i}} \exp \left(-a_{3 i} x^{a_{4 i}}\right), p_{i}=a_{5 i}+a_{6 i} x^{a_{7 i}},
\end{array}
$$

where $y$ - indicator (dependent variable), $i$ - number of the making statistical model (1), $m$ - the number of members of model depending on achievement of the remains from (1) error of measurements, $x$ - explanatory variable, $A_{i}$ - amplitude (half) of fluctuation (ordinate), $p_{i}$ - half-cycle of fluctuation (abscissa), $a_{1} \ldots a_{8}-$ the parameters of model (1) determined in the program environment CurveExpert (URL: http://www.curveexpert.net/).

On a formula (1) with two fundamental physical constants $e$ (Napier's number or number of time) and $\pi$ (Archimedes's number or number of space) the quantized wavelet signal is formed from within the studied phenomenon and/or process.

\section{Basic data for statistical modeling}

In geoecology different types of natural objects [6], and among them, undoubtedly are considered by us, the important place is taken by glaciers as climate regulators. In article of regularity of distribution of glaciers for 2013 are given for the first time.

On basic data [1] the fragment of the matrix including six factors is shown in table 
1 (identifiers are accepted according to the original).

Table 1. Matrix of basic data for statistical modeling

\begin{tabular}{|c|c|c|c|c|c|c|}
\hline \multirow{2}{*}{ Number } & $\begin{array}{c}\text { POINT_ } \\
\text { LATITUDE }\end{array}$ & $\begin{array}{c}\text { POINT_ } \\
\text { LONGITUDE }\end{array}$ & $\begin{array}{c}\text { POINT } \\
\text { ELEVATION }\end{array}$ & $\begin{array}{c}\text { POINT_ } \\
\text { WINTER_ } \\
\text { BALANCE }\end{array}$ & $\begin{array}{c}\text { POINT_ } \\
\text { SUMMER_ } \\
\text { BALANCE }\end{array}$ & $\begin{array}{c}\text { POINT } \\
\text { ANNUAL } \\
\text { BALANCE }\end{array}$ \\
\hline 1 & & EEE7 & EEE8 & EEE9 & EEE10 & EEE11 \\
\hline 2 & & & 100 & & & 100 \\
\hline$\ldots$ & $\ldots$ & $\ldots$ & $\ldots$ & $\ldots$ & $\ldots$ & $\ldots$ \\
\hline 71 & & & 1073 & & & -63 \\
\hline 72 & -54.78136 & -68.40169 & 1038 & 1015 & -644 & 371 \\
\hline 73 & -54.78182 & -68.40249 & 1036 & 947 & -540 & 406 \\
\hline$\ldots$ & $\ldots$ & $\ldots$ & $\ldots$ & $\ldots$ & $\ldots$ & $\ldots$ \\
\hline 101 & -54.78048 & -68.40171 & 1073 & 743 & -984 & -241 \\
\hline 102 & -16.3032 & -68.108 & 5053 & & & -958 \\
\hline 103 & -16.3025 & -68.1083 & 5056 & & & -1385 \\
\hline$\ldots$ & $\ldots$ & $\ldots$ & $\ldots$ & $\ldots$ & $\ldots$ & $\ldots$ \\
\hline 620 & & & 4058 & & & 120 \\
\hline 621 & & & 3796 & 20 & -3719 & -3699 \\
\hline 622 & & & 3828 & 99 & -2565 & -2466 \\
\hline$\ldots$ & $\ldots$ & $\ldots$ & $\ldots$ & $\ldots$ & $\ldots$ & $\ldots$ \\
\hline 2526 & 60.40417 & -148.9067 & 1053 & & & -2090 \\
\hline 2527 & 60.41974 & -148.9207 & 1283 & & & 0 \\
\hline 2528 & 60.42495 & -148.9371 & 1367 & & & 960 \\
\hline
\end{tabular}

Data are located asymmetrically (tab. 2).

Table 2. Quantity of the measured points of balance of mass of glaciers, piece.

\begin{tabular}{|l|c|c|c|c|c|c|}
\hline \multirow{2}{*}{$\begin{array}{c}\text { Influencing } \\
\text { factors } x\end{array}$} & \multicolumn{5}{c|}{ Dependent factors (indicators $y$ ) } \\
\cline { 2 - 8 } & EEE6 & EEE7 & EEE8 & EEE9 & EEE10 & EEE11 \\
\hline EEE6 - POINT LATITUDE [decimal degree ] & 1623 & 1623 & 1623 & 388 & 388 & 1591 \\
\hline EEE7 - POINT LONGITUDE [decimal degree ] & 1623 & 1623 & 1623 & 388 & 388 & 1591 \\
\hline EEE8 - POINT ELEVATION [m a.s.l.] & 1623 & 1623 & 2467 & 531 & 531 & 2467 \\
\hline EEE9 - POINT WINTER BALANCE [mm w.e.] & 388 & 388 & 531 & 531 & 531 & 531 \\
\hline EEE10 - POINT SUMMER BALANCE [mm w.e.] & 388 & 388 & 531 & 531 & 531 & 531 \\
\hline EEE11 - POINT ANNUAL BALANCE [mm w.e.] & 1591 & 1591 & 2467 & 531 & 531 & 2467 \\
\hline
\end{tabular}

Each of factors can have two states: first, a factor as the influencing variable $x$; secondly, the same factor is accepted as a dependent indicator of $y$. On them it is possible to assume that amplitude and the period of fluctuations on the general model (1) submit to the biotechnical law [2-5]. Because of uncertainty of the direction of a vector "better $\rightarrow$ worse" at values of each factor we don't reveal regularity the rank distributions. Therefore the rating of glaciers is also not carried out.

In this regard the correlation coefficient the rank distributions is equal 1 , and the factorial analysis we will carry out at all $6^{2}-6=30$ binary relations.

\section{A rating of factors as the influencing variables and indicators}

The method of the factorial analysis offered by us allows not to think a priori of ratios between separate parameters of the studied system (system contains 2528 glaciers in our example from the table 1). As a result the psychological barrier at researchers gets off: many binary relations for them will be unexpected. Therefore as our practice 
[6] showed, the factorial analysis the unique equation of type (1) allows to find unexpected scientific solutions in the field of research [7-12]. If some factorial communications are unusual and thus are highly adequate, new technical solutions are theoretically shown here. And often at the level of inventions of world novelty [12]. Thus the repeating process identification of the law (1) on one binary relation we designated the wavelet analysis $[9,11]$.

Without waves, that is changes only on amplitude at very long wave, incommensurably bigger on the fluctuation period to an interval of measurements, are formed the so-called determined binary relations. All of them are special cases of a formula (1).

The square correlation matrix received after the analysis of the binary relations between all six variables accepted on basic data from table 1 is given in table 3 . Here the rating of factors is given.

Table 3. Correlation matrix and rating of factors on the binary relations

\begin{tabular}{|c|c|c|c|c|c|c|c|c|}
\hline \multirow{2}{*}{$\begin{array}{l}\text { Influencing } \\
\text { factors } x\end{array}$} & \multicolumn{6}{|c|}{ Dependent factors (indicators $y$ ) } & \multirow{2}{*}{$\begin{array}{l}\text { Sum } \\
\sum r\end{array}$} & \multirow{2}{*}{$\begin{array}{c}\text { Place } \\
I_{x}\end{array}$} \\
\hline & EEE6 & EEE7 & EEE8 & EEE9 & EEE10 & EEE11 & & \\
\hline EEE6 & 1 & 0.9732 & 0.9491 & 0.4425 & 0.3985 & 0.4551 & 4.2184 & 2 \\
\hline EEE7 & 0.9688 & 1 & 0.4305 & 0.4154 & 0.4629 & 0.4156 & 3.6932 & 3 \\
\hline EEE8 & 0.8178 & 0.8611 & 1 & 0.7201 & 0.6835 & 0.4421 & 4.5246 & 1 \\
\hline EEE9 & 0.2237 & 0.4492 & 0.5431 & 1 & 0.2265 & 0.4721 & 2.9146 & 6 \\
\hline EEE10 & 0.6408 & 0.5571 & 0.1557 & 0.2301 & 1 & 0.7309 & 3.3146 & 5 \\
\hline EEE11 & 0.3703 & 0.4978 & 0.1719 & 0.5363 & 0.7592 & 1 & 3.3355 & 4 \\
\hline Sum $\sum r$ & 4.0214 & 4.3384 & 3.2503 & 3.3444 & 3.5306 & 3.5158 & 22.0009 & - \\
\hline Place $I_{y}$ & 2 & 1 & 6 & 5 & 3 & 4 & - & 0.6111 \\
\hline
\end{tabular}

Note. Trends from a wave component are allocated.

The coefficient of a correlative variation for 2528 glaciers of Earth is equal 22.0009 / $6^{2}=0.6111$. This criterion is applied when comparing various systems, for example, of different groups of glaciers with each other. Perhaps also comparison of all glaciers with other objects sew planets, for example, with deserts or with agroecological classes of a soil cover.

From six influencing variables on the first place there was EEE8 factor. On the second place EEE6 factor, and was located on the third place - EEE7. Among dependent indicators on the first place there is EEE7 factor. In second place is the factor EEE6, and the third -EEE10.

\section{Strong binary relations}

At correlation coefficient more than 0.7 binary relations between factors become strong (tab. 4As a rule, the accounting of wave indignation, additional to a trend, gives significant increase in adequacy to the revealed regularity on a formula (1). But glaciers do not yet have good data, because many of the values of the six factors have empty cells: the best matrix is a table completely filled with cells.

Because of low completeness of a matrix from 30 formulas received only eight strong communications that makes $22.2 \%$. Thus as the influencing variable EEE9 factor - POINT WINTER BALANCE was excluded. But as dependent indicators remained all six factors. From eight strong communications three (37.50\%) treat trends. 
Table 4. Correlation matrix of the strong binary relations at $r>0.7$

\begin{tabular}{|l|c|c|c|c|c|c|}
\hline \multirow{2}{*}{$\begin{array}{c}\text { Influencing } \\
\text { factors } x\end{array}$} & \multicolumn{5}{c|}{ Dependent factors (indicators $y)$} \\
\cline { 2 - 7 } & EEE6 & EEE7 & EEE8 & EEE9 & EEE10 & EEE11 \\
\hline EEE6 - POINT LATITUDE & & $\mathbf{0 . 9 7 3 2}$ & 0.9491 & & & \\
\hline EEE7 - POINT LONGITUDE & $\mathbf{0 . 9 6 8 8}$ & & & & & \\
\hline EEE8 - POINT ELEVATION & $\mathbf{0 . 8 1 7 8}$ & $\mathbf{0 . 8 6 1 1}$ & & $\mathbf{0 . 7 2 0 1}$ & & \\
\hline EEE10 - POINT SUMMER BALANCE & & & & & & 0.7309 \\
\hline EEE11 - POINT ANNUAL BALANCE & & & & & 0.7592 & \\
\hline
\end{tabular}

Hierarchy of strong communications following (tab. 5): 1) 0.9732 - EEE7 = $\mathrm{f}($ EEE6); 2) 0.9688 - EEE6 = f(EEE7); 3) 0.9491 - EEE8 = f(EEE6); 4) 0.8611 - EEE7 $=\mathrm{f}($ EEE8) $;$ 5) $0.8178-$ EEE6 = $\mathrm{f}($ EEE8); 6) $0.7592-$ EEE10 = $\mathrm{f}($ EEE11 $)$; 7) $0.7309-$ EEE11 = $\mathrm{f}($ EEE10); 8) 0.7201 - EEE9 = f(EEE8).

In table 5 (fig. 1-7) parameters of statistical models on the general formula (1) which values are written down in a compact matrix form with five significant figures are given.

Table 5. Parameters of the strong binary relations at correlation coefficient $r \geq 0,7$

\begin{tabular}{|c|c|c|c|c|c|c|c|c|c|}
\hline \multirow{3}{*}{$\begin{array}{l}\text { Indi- } \\
\text { cators } \\
y\end{array}$} & \multicolumn{8}{|c|}{ Asymmetric wavelet $y_{i}=a_{1 i} x^{a_{2 i}} \exp \left(-a_{3 i} x^{a_{4 i}}\right) \cos \left(\pi x /\left(a_{5 i}+a_{6 i} x^{a_{7 i}}\right)-a_{8 i}\right)$} & \multirow{3}{*}{$\begin{array}{c}\text { Correl } \\
\text { coeffic } \\
r\end{array}$} \\
\hline & \multicolumn{4}{|c|}{ amplitude (half) of fluctuation } & \multicolumn{3}{|c|}{ fluctuation half-cycle } & \multirow{2}{*}{$\frac{\text { shift }}{a_{8 i}}$} & \\
\hline & $a_{1 i}$ & $a_{2 i}$ & $a_{3 i}$ & $a_{4 i}$ & $a_{5 i}$ & $a_{6 i}$ & $a_{7 i}$ & & \\
\hline \multicolumn{10}{|c|}{ The influence EEE6 [decimal degree] } \\
\hline \multirow{3}{*}{$\begin{array}{l}\text { EEE}^{1}{ }^{1} \\
\text { Fig. } 1\end{array}$} & 4.23078 & 0 & -0.16452 & 0.54045 & 0 & 0 & 0 & 0 & \multirow{3}{*}{0.9732} \\
\hline & -0.31020 & 1.48076 & 0 & 0 & 0 & 0 & 0 & 0 & \\
\hline & 132.72384 & 0 & $8.79872 \mathrm{e}-5$ & 1.76602 & 4.87479 & 0.29176 & 0.56033 & 0.24849 & \\
\hline \multirow{2}{*}{$\begin{array}{l}\text { EEE8 }{ }^{1} \\
\text { Fig. } 1\end{array}$} & $1.66509 \mathrm{e} 6$ & 0 & 0.31234 & 0.94742 & 0 & 0 & 0 & 0 & \multirow{2}{*}{0.9491} \\
\hline & $7.82146 \mathrm{e}-5$ & 4.91282 & 0.018337 & 1.20027 & 0 & 0 & 0 & 0 & \\
\hline \multicolumn{10}{|c|}{ The influence EEE7 [decimal degree] } \\
\hline \multirow{4}{*}{$\begin{array}{c}\text { EEE6 }^{2} \\
\text { Fig. } 2\end{array}$} & 64.56655 & 0 & 0.00076040 & 1.01838 & 0 & 0 & 0 & 0 & \multirow{4}{*}{0.9688} \\
\hline & $-1.24710 \mathrm{e}-15$ & 6.59346 & 0 & 0 & 0 & 0 & 0 & 0 & \\
\hline & $-2.35962 \mathrm{e}-7$ & 5.20107 & 0.042456 & 1 & 12.92183 & 0.0036148 & 1.03167 & 2.65582 & \\
\hline & -0.00052866 & 3.02216 & 0.025670 & 1 & 3.80507 & $9.27492 \mathrm{e}-5$ & 1 & 4.71131 & \\
\hline \multicolumn{10}{|c|}{ The influence EEE8 [ $m$ a.s.l.] } \\
\hline \multirow{3}{*}{$\begin{array}{l}\text { EEE7 } \\
\text { Fig. } 3\end{array}$} & -87.70507 & 0 & $-8.09363 e-5$ & 1.07588 & 0 & 0 & 0 & 0 & \multirow{3}{*}{0.8611} \\
\hline & $2.50470 \mathrm{e}-6$ & 2.55776 & 0.00026769 & 1.12617 & 0 & 0 & 0 & 0 & \\
\hline & \begin{tabular}{|l|}
$-9.59526 e-8$ \\
\end{tabular} & 3.19687 & 0.0017158 & 0.99993 & 157.16690 & 0.28654 & 0.88567 & 6.01043 & \\
\hline \multirow{3}{*}{$\begin{array}{l}\text { EEE6 } \\
\text { Fig. } 4\end{array}$} & 7.25053 & 0 & -0.00032396 & 1.09546 & 0 & 0 & 0 & 0 & \multirow{3}{*}{0.8178} \\
\hline & $-6.85611 e-17$ & 5.03862 & 0 & 0 & 0 & 0 & 0 & 0 & \\
\hline & \begin{tabular}{|l|}
-0.00012515 \\
\end{tabular} & 2.24860 & 0.0020534 & 1 & 2922.5439 & -0.48413 & 0.99988 & -2.92162 & \\
\hline \multirow{3}{*}{$\begin{array}{l}\text { EEE9 } \\
\text { Fig. } 5\end{array}$} & 59.61396 & 0 & -0.14457 & 0.46269 & 0 & 0 & 0 & 0 & \multirow{3}{*}{0.7201} \\
\hline & $-2.90947 e-7$ & 3.11597 & 0 & 0 & 0 & 0 & 0 & 0 & \\
\hline & -0.00062264 & 2.34099 & 0.0018640 & 1.00057 & 846.23612 & -0.042840 & 0.99814 & -0.80809 & \\
\hline \multicolumn{10}{|c|}{ The influence EEE11 [mm w.e.] } \\
\hline \multirow{2}{*}{$\begin{array}{c}\text { EEE10 } \\
\text { Fig. } 6\end{array}$} & -28940.548 & 0 & 0 & 0 & 0 & 0 & 0 & 0 & \multirow{2}{*}{0.7592} \\
\hline & 270.01817 & 0.52442 & $2.61663 e-5$ & 0.99761 & 0 & 0 & 0 & 0 & \\
\hline \multicolumn{10}{|c|}{ The influence EEE10 [mm w.e.] } \\
\hline $\mathrm{EEE}_{11}^{3}$ & -11303.0999 & 0 & 0 & 0 & 0 & 0 & 0 & 0 & \multirow{2}{*}{0.7308} \\
\hline Fig. 7 & 9.38697 & 0.76192 & 0 & 0 & 0 & 0 & 0 & 0 & \\
\hline
\end{tabular}

Notes: ${ }^{1} x=x+90 ;{ }^{2} x=x+190 ;{ }^{3} x=x+12000$.

From data of table 5 it is visible that some regularities required replacement of variables because of negative values of the influencing variables. 

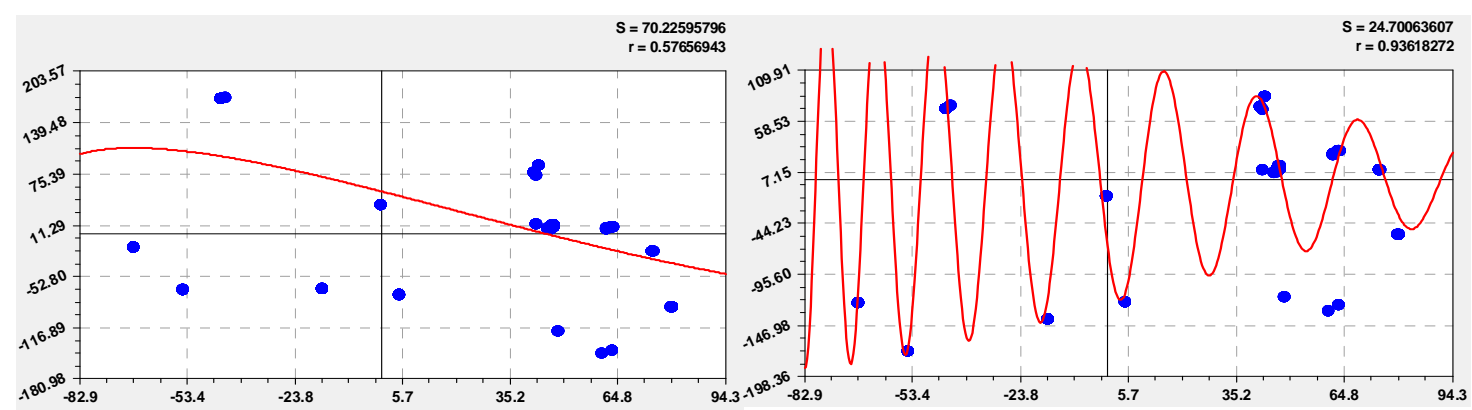

Trend from two members EEE7

Fluctuation EEE7

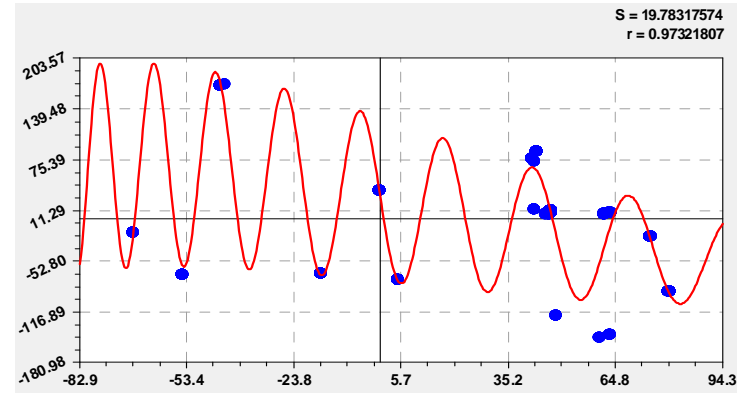

Trend and fluctuation EEE7

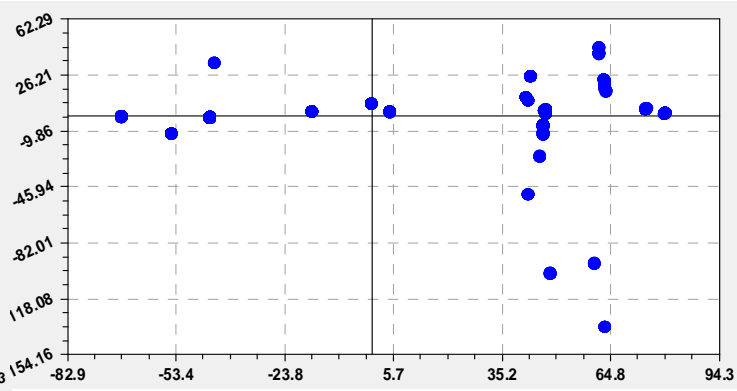

Remains EEE7 after three members of model
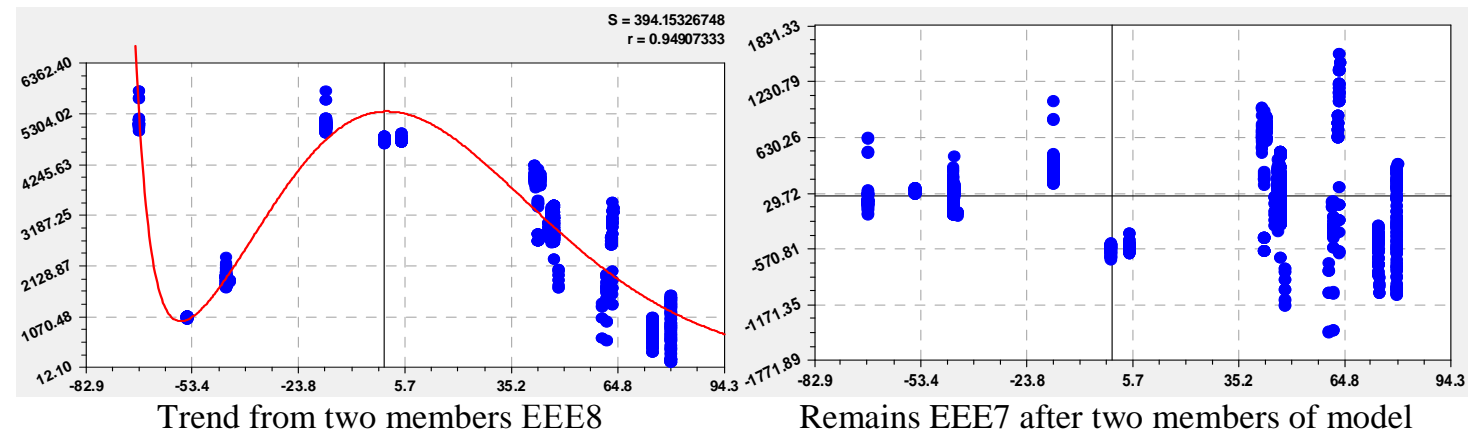

Remains EEE7 after two members of model

Figure 1. Schedules of models of influence of a factor of EEE6 on change of factors of EEE7 and EEE8

From schedules in figure 1 it is visible that the function EEE7 $=f(E E E 6)$ supports three members from whom the first two are a difference of two laws: first, law of exponential growth; secondly, indicative law. The third component is wavelet on a formula (1) with very high coefficient of correlation 0.9362 . Therefore the main contribution to formation of the binary relation is carried out by wave function with a variable amplitude under the law of exponential death and the variable period of fluctuation. Thus the initial stage of fluctuation is equal $2 \times 4.87479 \approx 9.75$ degrees. In process of increase in width fluctuation calms down because of growth of a half-cycle.

Remains EEE7 after three members of model have significant values at the latitudes of 40-65 degrees. Therefore if it is necessary, the wavelet analysis of microwaves on the remains for this width is possible further.

The EEE8 function $=\mathrm{f}($ EEE6) $)$ it consists of only the binomial trend. According to table 5 it contains the sum from two laws: first, law of exponential death; secondly, biotechnical law [2-5]. The remains show small fluctuation which can be identified a formula (1), however adequacy of a wave component will be very small.

Other schedules have similar explanations. Therefore glaciers, as well as other types of natural objects [6], have natural distributions. 

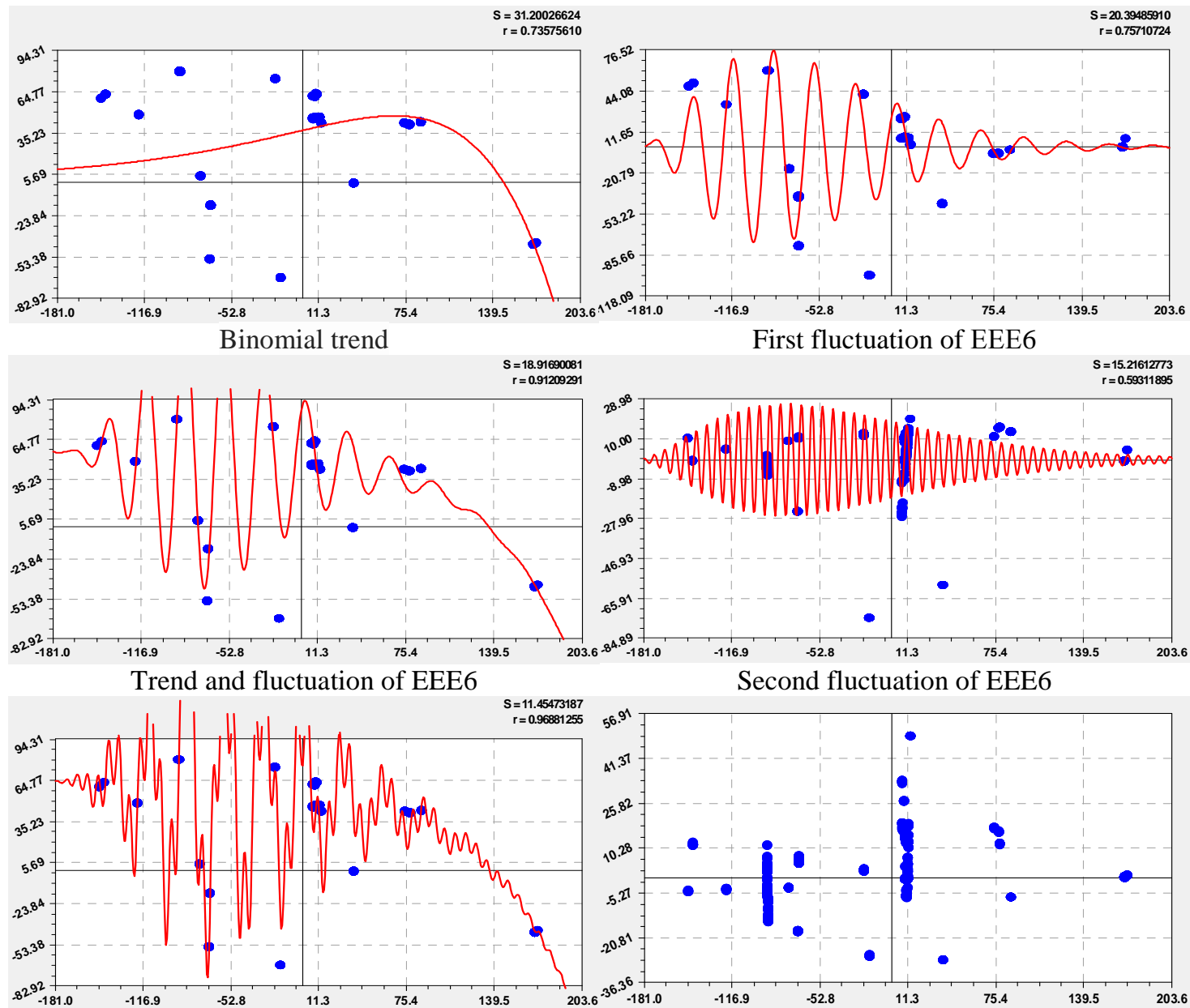

Second fluctuation of EEE6

Trend and two fluctuations

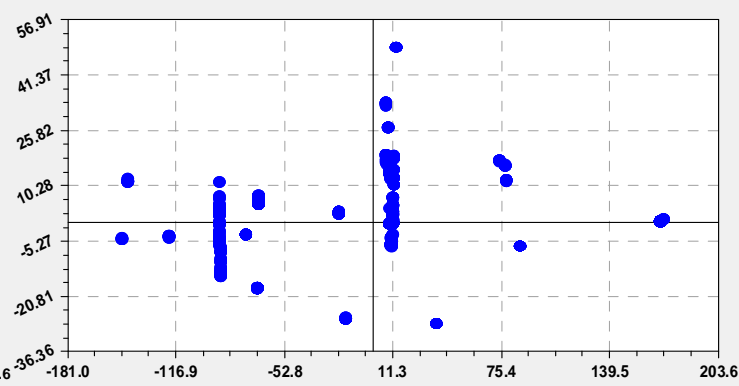

Remains EEE6 after four-membered model

Figure 2. Schedules of models of influence of EEE7 on change of EEE6

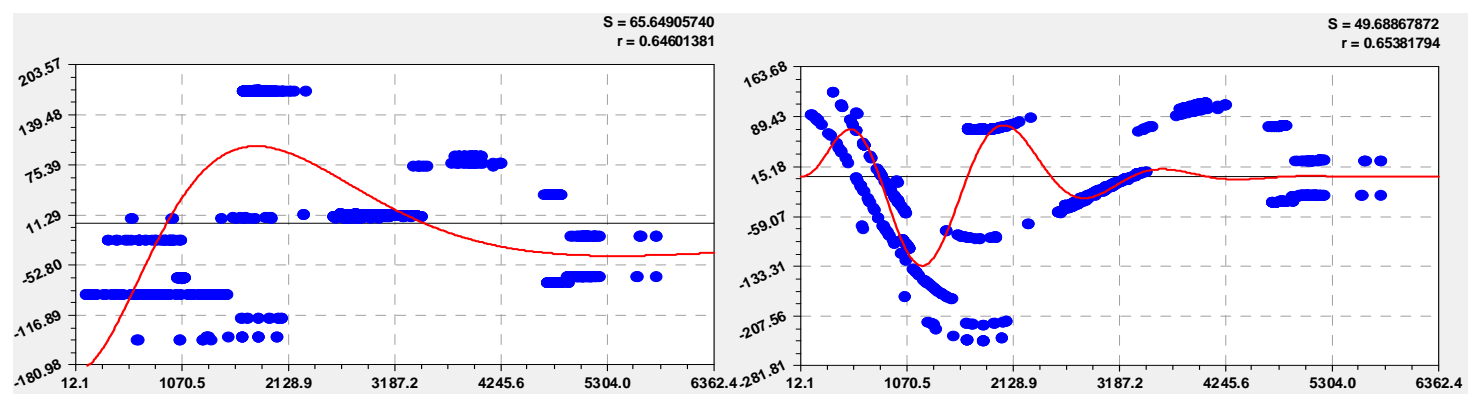

Trend in the form of the sum of two laws

Fluctuation

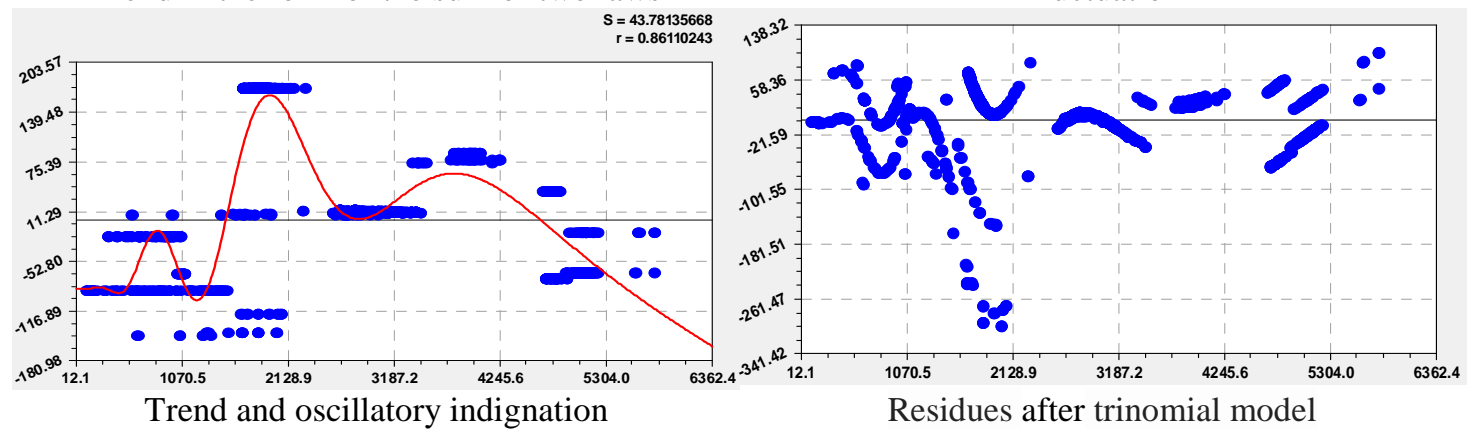

Figure 3. Schedules of models of influence of EEE8 on change of EEE7 

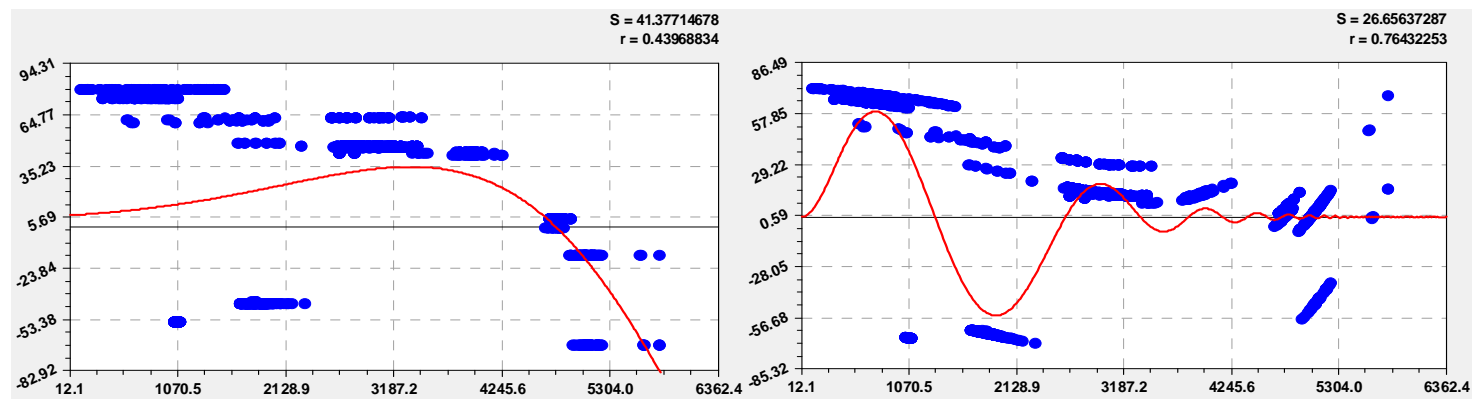

Trend in the form of the sum of two laws

Fluctuation

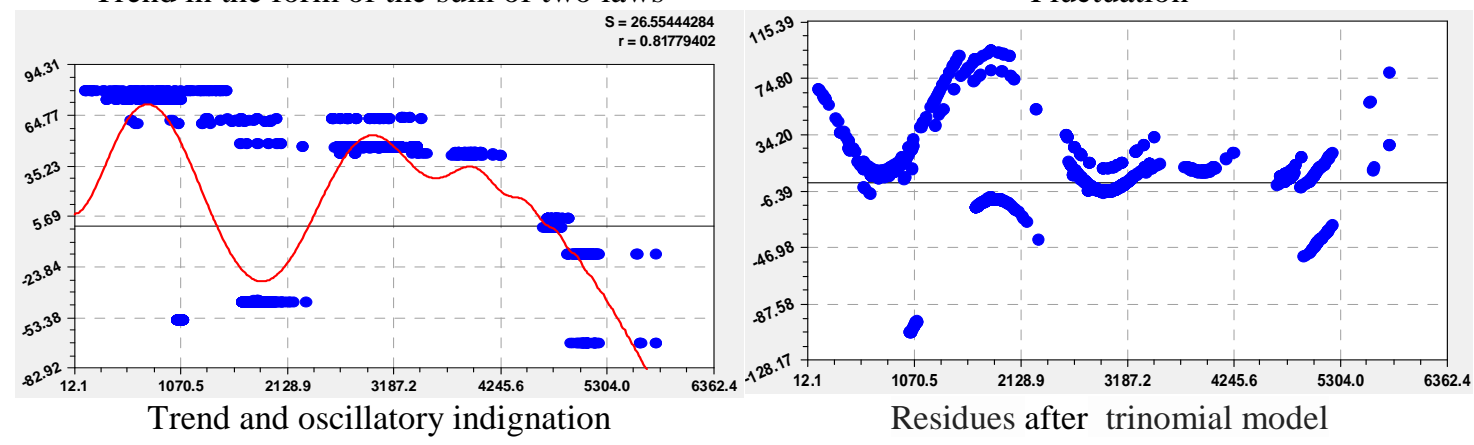

Figure 4. Schedules of models of influence of EEE8 on change of EEE6

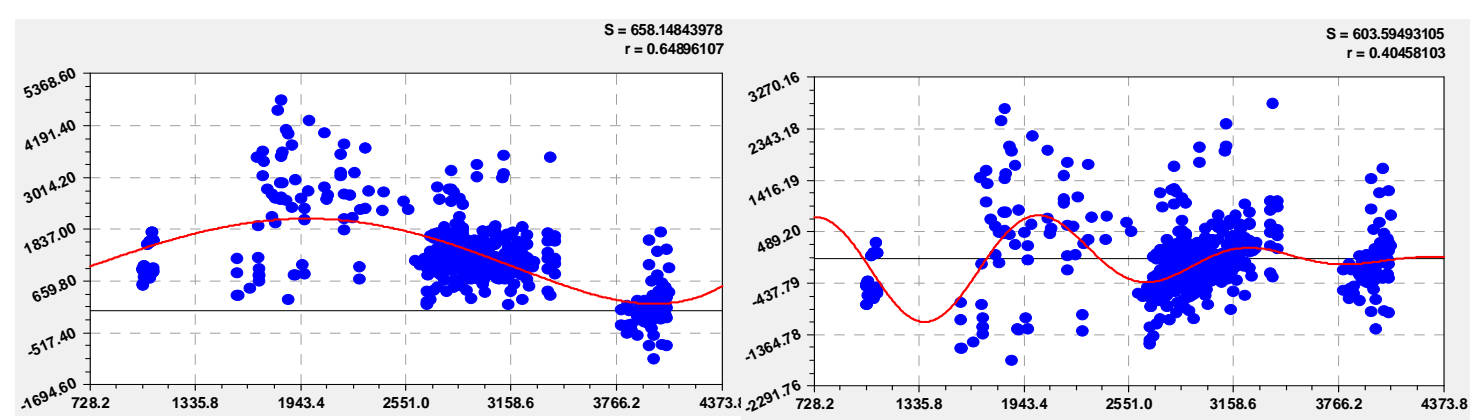

Trend in the form of the sum of two laws

Fluctuation

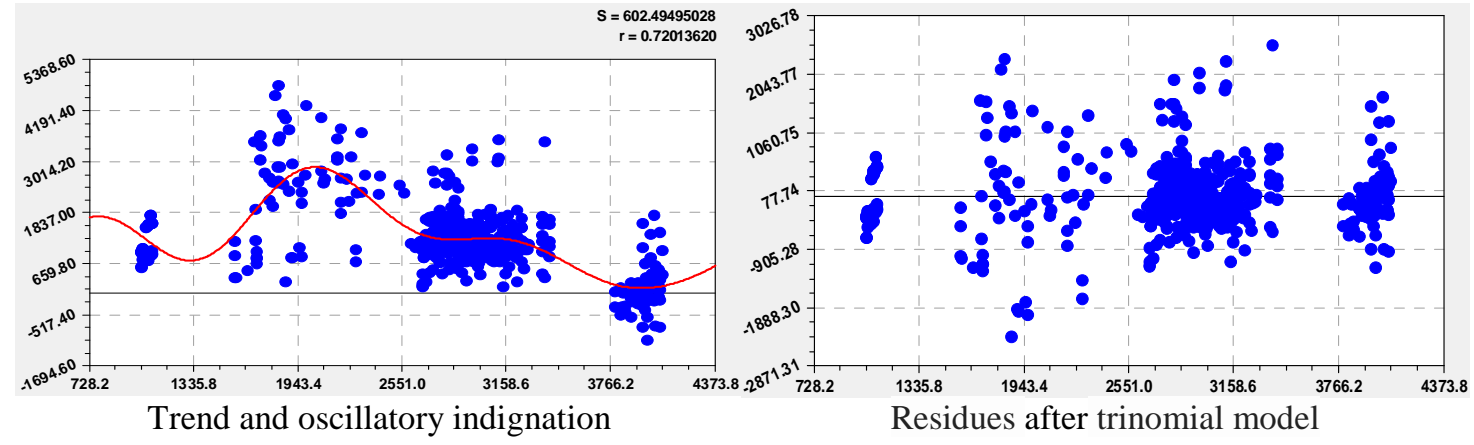

Figure 5. Schedules of models of influence of EEE8 on change of EEE9

The maximum number of members of the statistical model EEE6 $=\mathrm{f}($ EEE7) is equal to four that corresponds to computing opportunities of the program CurveExpert1.40 environment.

For the full wavelet analysis it is necessary to develop the special program environment according to our scenarios of statistical modeling for a supercomputer of a petaflop class. Thus the new program environment for large volumes of the table of basic data will be universal for science. 


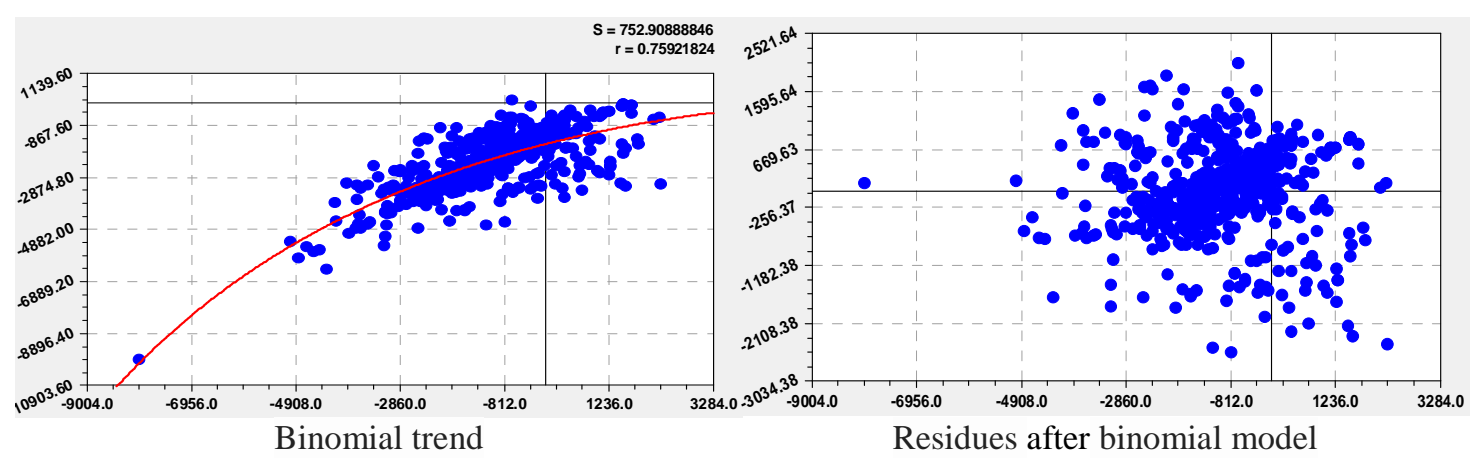

Figure 6. Schedules of models of influence of EEE11 on change of EEE10

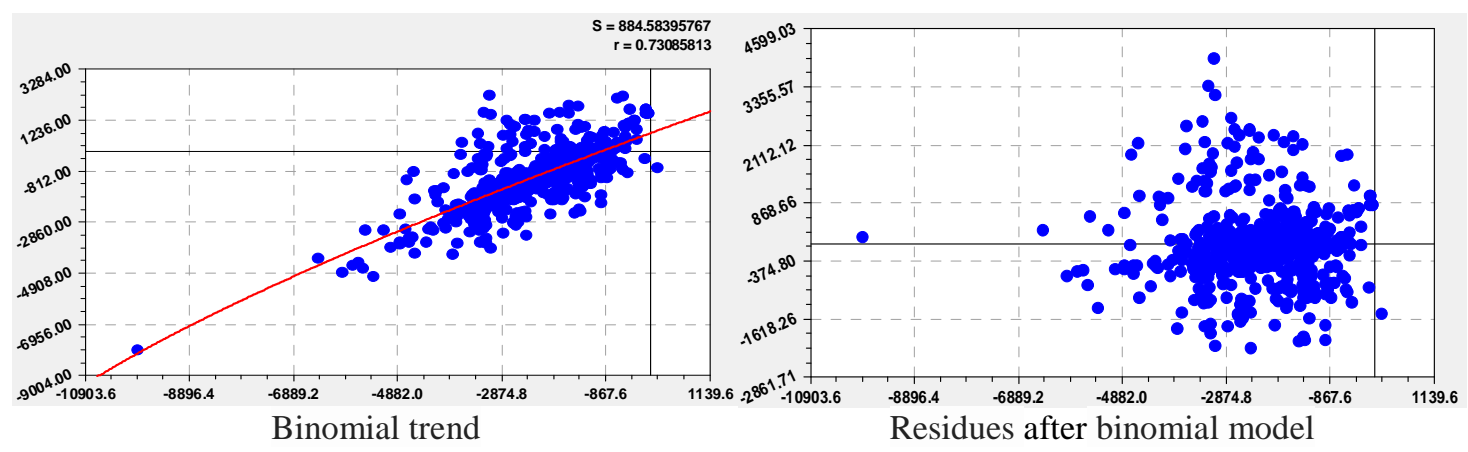

Figure 7. Schedules of models of influence of EEE10 on change of EEE11

The analysis of schedules according to amplitude-frequency characteristics shows that the system of glaciers possesses a certain property of wave adaptation to living conditions on the planet Earth.

For some binary relations the number of members in the general statistical model can exceed 100-120 pieces. In this case there is a possibility of carrying out the fractal analysis for group of wavelets on mega, macro, meso and to microfluctuations.

\section{Conclusions}

Applicability of statistical model (1) to parameters of points of fluctuations of balance at the mass of glaciers of Earth is proved. As a result each binary relation contains a trend and wavelet signals. And the trend is a special case of fluctuation of a wavelet, superlong on the period. As a result the general statistical model represents the plait consisting of a set of lonely waves with variables amplitude and the period of fluctuations. After statistical modeling the factorial analysis allowing to make ratings of factors as the influencing parameters and as dependent indicators is carried out.

The offered methodology of identification allows to allocate waves of the binary relations between the measured factors at glaciers. Thus for 2528 glaciers of subgroup of EEE finite-dimensional wavelets which can be compared further with heuristic representations of experts are characteristic. The method of identification allows to allocate significant parameters of glaciers and the binary relations between them in which it will be necessary to increase the accuracy of future measurements. Thus from different subgroups we allocated 26 factors, but their joint analysis is disturbed by a disagreement between tables of data. 


\section{References}

[1] Fluctuations of Glaciers Database. World Glacier Monitoring Service (WGMS). 2014. FoG-DB-Version_2013-11. http://wgms.ch/data-exploration/databaseversions/. DOJ 10.5904/wgms-fog-2013-11.

[2] P.M. Mazurkin. Biotechnical law and designing of adequate models // Achievements of modern natural sciences 2009. No. 9. P. 125-129.

[3] P.M. Mazurkin. The biotechnical law, algorithm in intuitive sense and algorithm of search of parameters // Achievements of modern natural sciences. 2009. №. 9. P. 88-92.

[4] P.M. Mazurkin. The biotechnical principle in statistical modeling // Achievements of modern natural sciences. 2009 . No. 9. P. 107-111.

[5] P.M. Mazurkin. Biotechnical principle and steady laws of distribution // Achievements of modern natural sciences. 2009. No. 9 of Page 93-97. URL: www.rae.ru/use/?section $=$ content\&op $=$ show article\&article $i d=7784060$.

[6] P.M. Mazurkin. Geoecology: Patterns of Modern Natural Science. Yoshkar-Ola: MarSTU, 2006. 336 p.

[7] P.M. Mazurkin. Identification of statistical steady regularities // Science and world: international scientific magazine. 2013. № 3(3). P. 28-33.

[8] P.M. Mazurkin. Invariants of the Hilbert Transform for 23-Hilbert Problem, Advances in Sciences and Humanities. Vol. 1, No. 1, 2015, pp. 1-12. doi: 10.11648/j.ash.20150101.11

[9] P.M. Mazurkin. Method of identification // $14^{\text {th }}$ International multidisciplinary scientific geoconferenct \& SGEM2014. GeoConference jn NANO. BIO AND GREEN - TECHNOLOGIES FOR A SUSTAINABLE FUTURE. Conference proceedincs. Volume 1. Section Advances in Biotechnology. 17-26 June 2014. Albena. Bulgaria. P. 427-434.

[10] P.M. Mazurkin. The decision 23-oh Gilbert's problems. Interdisciplinary researches in the field of mathematical modeling and informatics. Materials of the 3rd scientific and practical Internet conference. Ulyanovsk: SIMJET. 2014. P. 269-277.

[11] P.M. Mazurkin. Statistical modeling of entire prime numbers / International Journal of Engineering and Technical Research (IJETR) ISSN: 2321-0869. Volume-2. Issue-8. August 2014. P.148-158.

[12] P.M. Mazurkin. A.S. Filonov. Mathematical modeling. Identification of onefactorial statistical regularities: manual. Yoshkar-Ola: MarSTU. 2006. 292 p. 